\title{
VIABILIDADE ECONÔMICA DE AQUISIÇÃO DE UM SILO-SECADOR PARA PEQUENAS ÁREAS DE PRODUÇÃO
}

\section{SAMIR P. JASPER ${ }^{1}$, MARCO A. M. BIAGGIONI ${ }^{2}$, JADER P. RIBEIRO ${ }^{3}$}

\begin{abstract}
RESUMO: O objetivo deste trabalho foi avaliar, por meio de simulação econômica, a viabilidade de aquisição de um silo-secador, para pequenas propriedades rurais, tendo como referências as opções de terceirizar o processo de secagem/armazenagem ou a comercialização do milho úmido. Em virtude da alta diversificação encontrada nas pequenas propriedades rurais, a simulação foi realizada considerando-se diferentes tamanhos de áreas exploradas com milho (10; 20; 30 e 40 ha), níveis de produtividade (3.900; 4.500 e $5.100 \mathrm{~kg} \mathrm{ha}^{-1}$ ) e preços por saca de milho ( $\mathrm{R} \$ 13,03$; $\mathrm{R} \$ 19,69$ e R\$ 34,29), no Estado de São Paulo. Comparando as rentabilidades obtidas, notou-se a superioridade da receita líquida na aquisição do silo secador nas áreas de produção de 20 ha com produtividade de 4.500 e $5.100 \mathrm{~kg} \mathrm{ha}^{-1}$, 30 ha e 40 ha nos vários níveis de produtividade (3.900; 4.500 e $5.100 \mathrm{~kg} \mathrm{ha}^{-1}$ ) sempre que o preço de mercado da saca de milho cobriu os custos anuais do sistema. A terceirização da secagem/armazenagem apresentou-se como a melhor alternativa nas áreas de 10 ha (todas as produtividades) e 20 ha (produtividade de $3.900 \mathrm{~kg} \mathrm{ha}^{-1}$ ). A comercialização do produto úmido nunca se constituiu na opção mais rentável.
\end{abstract}

PALAVRAS-CHAVE: silo secador, milho, simulação econômica.

\section{ECONOMIC VIABILITY ACQUISITION OF A DRYING-STORING FACILITY, DESIGNED FOR SMALL FARMS}

\begin{abstract}
The aim of this work was to evaluate, by using economical simulation, the viability to get a drying-storing facility, for small farms. This option was compared with two others conditions: to pay the processing or to market high moisture content grains. The study was carried out in properties with $10 ; 20 ; 30$ and 40 ha, productivity levels of 3,900;4,500 and 5,100 kg ha-1 and prices for corn bag (60 kg) of $\mathrm{R} \$ 13.03, \mathrm{R} \$ 19.69$ and $\mathrm{R} \$ 34.29$, in the State of Sao Paulo, Brazil. The results indicated the superiority of the profits to get the drying-storing facility option for properties with 20 ha (productivity levels of 4,500 and 5,100 $\mathrm{kg} \mathrm{ha}^{-1}$ ), 30 ha and 40 ha, while to pay the processing (drying and storage) showed a better option for properties with 10 ha (all productivity levels) and $20 \mathrm{ha}\left(3,900 \mathrm{~kg} \mathrm{ha}^{-1}\right)$. To market high moisture content grains option never provided the best profitability.
\end{abstract}

KEYWORDS: in-bin drying, corn, economical simulation.

\section{INTRODUÇÃO}

Segundo dados da Organização das Nações Unidas para a Agricultura e o Abastecimento (FAO, 2003), a agricultura familiar é responsável por $40 \%$ da produção de alimentos do País, representando $38 \%$ do valor bruto da produção nacional e $25 \%$ das terras cultivadas. Na produção de grãos, os pequenos agricultores produzem $67 \%$ do feijão e $49 \%$ do milho colhido no País, entre outros.

Conforme divulgado pela EMBRAPA (2001), as instituições de pesquisa e desenvolvimento agropecuário estão firmemente comprometidas com o desenvolvimento da agricultura familiar e investiram, em 2000 , cerca de $\mathrm{R} \$ 98$ milhões em projetos destinados a aumentar o número de

\footnotetext{
${ }^{1}$ Eng $^{\mathrm{o}}$ Agrônomo, Mestrando do Programa de Pós-Graduação em Energia na Agricultura, UNESP - Botucatu - SP, jasper@fca.unesp.br

${ }^{2}$ Prof. Doutor, Departamento de Engenharia Rural, UNESP - Botucatu - SP, Fone: (0XX14)3811-7165, biaggioni@ fca.unesp.br

${ }^{3}$ Mestrando do Programa de Pós-Graduação em Energia na Agricultura, UNESP - Botucatu - SP.

Recebido pelo Conselho Editorial em: 4-10-2005
}

Aprovado pelo Conselho Editorial em: 9-9-2006 
empregos, gerar produtos de qualidade e com menor custo, estabilizar a produção e a oferta de produtos básicos, além de preservar o meio ambiente.

O armazenamento na fazenda constitui prática de suma importância, tanto para o complemento da estrutura armazenadora urbana quanto para minimizar perdas quantitativas e qualitativas a que estão sujeitos os produtos colhidos. Sabe-se que, no Brasil, dependendo da região, as perdas podem atingir $20 \%$ ou mais e são ocasionadas pelo ataque de pragas, devido à inadequação de instalações e à falta de conhecimentos técnicos adequados (WEBER, 2005).

MARTINS et al. (2002) citam que os produtores familiares sofrem de problemas crônicos de acesso aos recursos tecnológicos e financeiros, enfrentando inúmeras dificuldades para colocar seus produtos no mercado e, com isso, sujeitam-se às desvantajosas condições impostas pelos intermediários de quem dependem. Dessa forma, sua rentabilidade econômica é limitada, vendem seus produtos na safra, época em que, historicamente, se verificam os menores preços, chegando, em alguns casos, à metade do valor alcançado na entressafra.

No Brasil, o armazenamento em fazendas é ainda inexpressivo, atingindo, no máximo, $9 \%$ da capacidade total. Em países desenvolvidos como o Canadá, por exemplo, essa estimativa é de $80 \%$, e na Argentina esse número passa de 25\% (BESKOW \& DECKERS, 2002).

O sistema silo-secador, proposta desta análise, foi projetado com estrutura simples para atender a um custo adequado ao pequeno produtor, mas dotado de sistema de controle de temperatura automatizado, com fácil programação. Embora a secagem mecânica nas fazendas seja feita, ainda, por pequeno número de agricultores, não se pode afirmar que não existam experiências significativas dos avanços alcançados nessa área. Apesar dos problemas apresentados, inclusive de limitação de recursos disponíveis para pesquisas, MARTINS et al. (2002) afirmam que o esforço de técnicos e pesquisadores de algumas instituições vem proporcionando o desenvolvimento de equipamentos e sistemas de secagem de baixo custo, de fácil adaptação para o pequeno produtor, além de processos que permitem manter a qualidade dos grãos produzidos.

Secadores de grãos de pequena e média capacidade, construídos em alvenaria e equipados com fornalhas de alta eficiência energética, foram desenvolvidos na Universidade Federal de Viçosa e amplamente difundidos entre pequenos e médios produtores, de várias regiões brasileiras. Segundo SILVA et al. (2000), pequenos secadores de grãos que empregam diferentes tecnologias de fabricação vêm sendo desenvolvidos e testados por empresas de pesquisa e extensão, como a CESA - RS, EMATER - RS e Embrapa Suínos e Aves.

Segundo PORTELLA \& EICHELBERGER (2001), a velocidade de secagem é influenciada pelos parâmetros: umidade inicial dos grãos, temperatura (do ar de secagem e dos grãos), umidade relativa e fluxo de ar de secagem, fluxo de grão no secador, método de secagem empregado, espécie e cultivar, além do histórico dos grãos. Secagem muito rápida, em decorrência de altas temperaturas e grandes fluxos de ar, resulta num gradiente de umidade muito acentuado entre a superfície e o interior do grão, gerando tensões internas que comprometem a qualidade do produto. Por outro lado, a velocidade de secagem é um fator de ordem econômica muito importante, pois é inversamente proporcional à duração da secagem, isto é, quanto maior a velocidade de secagem, menor será o tempo de permanência dos grãos no secador, potencializando sua utilização.

Considerando que uma unidade armazenadora, tecnicamente projetada e convenientemente localizada, constitui alternativa para melhorar os retornos econômicos dos sistemas produtivos de grãos, o objetivo deste trabalho foi avaliar, por meio de simulação econômica, a viabilidade da aquisição de um sistema de secagem/armazenagem de grãos projetados para pequenos produtores de milho.

\section{MATERIAL E MÉTODOS}

O equipamento em estudo, denominado Silo Alambrado Ventilável, é constituído por uma câmara de secagem, sistema de ventilação, sistema de descarga e sistema controlador. Na Figura 1, apresenta-se uma vista em corte do silo estudado, descrevendo detalhadamente seus componentes. 
Os parâmetros considerados para a composição dos custos foram: energia elétrica (ventilador e rosca transportadora), mão-de-obra, manutenção, depreciação do equipamento e benfeitorias, seguro, taxas diversas e juros.

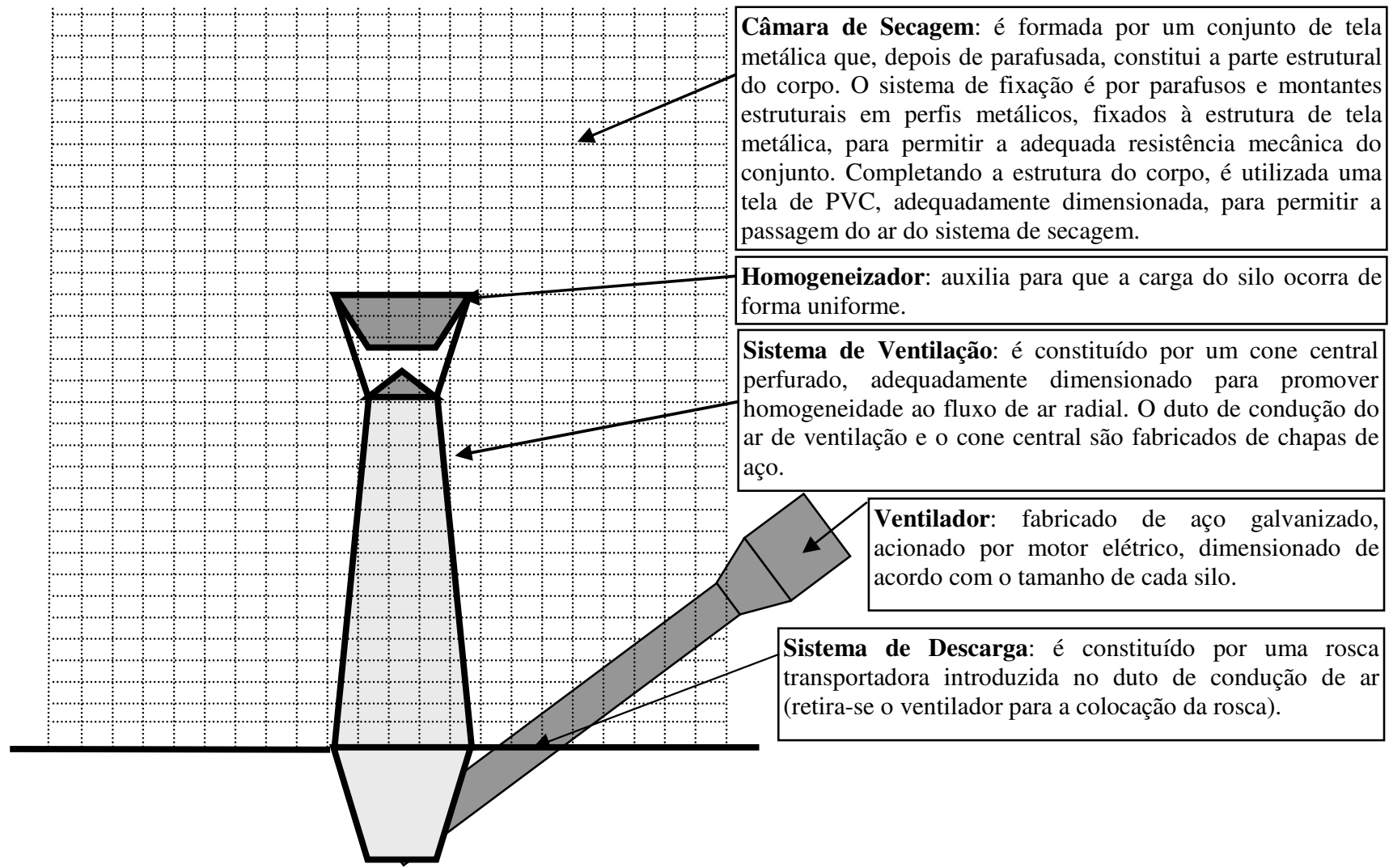

FIGURA 1. Vista em corte do silo-alambrado ventilável.

O custo de secagem foi estimado por meio do modelo proposto por CHANG et al. (1979), citados por SILVA (1995), sofrendo alguns ajustes, para melhor representatividade dos custos de secagem do silo. Nesta metodologia, o custo total de secagem foi estimado pela eq.(1):

$$
\mathrm{C}_{\text {Total }}=\left[\left(\mathrm{C}_{\mathrm{e}}+\mathrm{C}_{\mathrm{mo}}\right) \mathrm{V}\right]+\mathrm{C}_{\mathrm{f}}+\mathrm{C}_{\text {quebra }}
$$

em que,

$\mathrm{C}_{\text {Total - custo total de secagem, } \mathrm{R} \$ \text {; }}$

$\mathrm{C}_{\mathrm{e}}$ - custo de eletricidade para secagem, $\mathrm{R} \$ \mathrm{~m}^{-3}$;

$\mathrm{C}_{\mathrm{mo}}$ - custo de mão-de-obra para secagem, $\mathrm{R} \$ \mathrm{~m}^{-3}$;

$\mathrm{V}$ - volume a ser secado, $\mathrm{m}^{3}$;

$\mathrm{C}_{\mathrm{f}}$ - custo fixo, $\mathrm{R} \$$, e

$\mathrm{C}_{\text {quebra }}$ - custo de quebra técnica, $\mathrm{R} \$$.

O custo da eletricidade foi calculado pela eq.(2).

$$
\mathrm{C}_{\mathrm{e}}=\frac{\text { Pot } \mathrm{P}}{\mathrm{n}}
$$

em que,

Pot - potência despendida pelo ventilador, $\mathrm{kW} \mathrm{m}^{-3}$ de produto;

$\mathrm{P}$ - preço da eletricidade, $\mathrm{R} \$ \mathrm{~kW}^{-1}$, e

$\mathrm{n}$ - eficiência do sistema de ventilação (= 0,70 - SILVA, 1995).

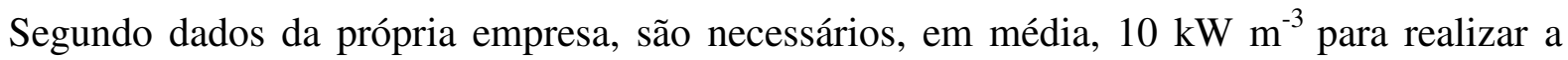
secagem do produto. Para a condução da aeração no próprio silo, durante o período de armazenagem, estimou-se consumo médio de $5 \mathrm{~kW} \mathrm{~m}^{-3}$, pelo período de seis meses, para as 
condições de Botucatu (FERREIRA et al., 1990). O preço de energia elétrica na zona rural no Estado de São Paulo é R \$ 0,17834 kW kW $^{-1}$ (CPFL, 2006). Não se incluiu o custo da energia envolvida na carga do silo, pois considerou-se a operação sendo realizada por gravidade, a partir da própria colhedora ou de caminhão.

Para o cálculo do custo da mão-de-obra, utilizou-se o valor do trabalhador "diarista" no Estado de São Paulo (IEA, 2005), ao longo do ano de 2005, que foi de R\$ 16,97. Efetuou-se a conversão em custo horário de mão-de-obra, sendo considerado $8 \mathrm{~h}$ diárias de trabalho. Conforme os dados fornecidos pela empresa, em média, necessita-se de $0,25 \mathrm{~h}$ de trabalho por metro cúbico de produto.

Os preços dos equipamentos e das benfeitorias, considerados novos, foram obtidos junto ao mercado. A depreciação foi estimada pelo método linear, considerando 15 anos de vida útil dos equipamentos e benfeitorias. As taxas diversas e os juros, em geral, foram considerados em $10 \%$ ao ano, calculados sobre o capital médio, e as despesas com manutenção em $2 \%$ ao ano, sobre o valor total de investimento.

Ao custo de quebra técnica, foram incorporadas as perdas de matéria seca ocorrida durante a secagem, devido à secagem em excesso ou incompleta e à perda na qualidade eq.(3).

$$
\mathrm{C}_{\text {Quebra }}=\mathrm{F}_{\mathrm{q}} \mathrm{P}_{\text {Produto }} \mathrm{V}_{\mathrm{t}}
$$

em que,

$\mathrm{C}_{\text {Quebra }}$ - custo de inadequação, $\mathrm{R} \$$;

$\mathrm{F}_{\mathrm{q}}$ - fator de quebra técnica $=0,005$ (SILVA, 1995);

$\mathrm{P}_{\text {Produto }}$ - preço do produto, $\mathrm{R} \$ \mathrm{~m}^{-3}, \mathrm{e}$

$\mathrm{V}_{\mathrm{t}}$ - quantidade total a ser secada, $\mathrm{m}^{3}$.

Segundo dados do IBGE (2004), no Estado de São Paulo, a maioria das propriedades rurais tem sua área variando de 10 a 99 ha, e a pequena propriedade rural tem sua área compreendida até 50 ha (20\% de reserva legal). Devido a esses fatores, a simulação da análise econômica foi feita para áreas de produção de 10; 20; 30 e 40 ha.

A partir de informações levantadas pelo Instituto de Economia Agrícola do Estado de São Paulo (IEA, 2006), a produtividade média da cultura do milho no Estado de São Paulo, nos últimos cinco anos, atingiu próximo de 4.449,80 kg (desvio-padrão de 164,83 kg). Em virtude dessa variação, considerou-se, nos cálculos, produtividade variando em $3.900 ; 4.500$ e $5.100 \mathrm{~kg} \mathrm{ha}^{-1}$ (65; 75 e 85 sacos ha ${ }^{-1}$ ), em cada área de produção.

Os custos de produção da cultura do milho (safra de verão 2005-2006), para o sistema de plantio direto, foram obtidos junto à Companhia Nacional de Abastecimento (CONAB, 2006). Esse custo foi levantado considerando uma faixa de produtividade de 4.200 a $6.000 \mathrm{~kg} \mathrm{ha}^{-1}$, com média de $4.800 \mathrm{~kg} \mathrm{ha}^{-1}$. O custo operacional total foi de $\mathrm{R} \$ 1.173,88 \mathrm{ha}^{-1}$, não se incorporando a remuneração esperada sobre o capital fixo e sobre a terra.

A fim de contemplar as variações que normalmente ocorrem no preço da saca de milho, considerou-se o comportamento ao longo de sessenta meses, utilizando-se do preço mínimo ( $\mathrm{R} \$ 13,03)$, do máximo ( $\mathrm{R} \$ 34,29)$ e do médio ( $\mathrm{R} \$ 19,69)$, no período de janeiro de 2001 a setembro de 2005. Estes preços foram obtidos junto ao Instituto de Economia Agrícola do Estado de São Paulo (IEA, 2006), sendo corrigidos através do Índice Geral de Preços da Fundação Getúlio Vargas (IGP/FGV, 2006).

Para efeito de comparação, estimou-se a viabilidade econômica da terceirização da secagem/armazenagem dos grãos, pelo período de 6 meses, sendo o custo do transporte até ao armazém de $\mathrm{R} \$ 9,87 \mathrm{t}^{-1}$, recepção de $\mathrm{R} \$ 1,33 \mathrm{t}^{-1}$, pesagem de $\mathrm{R} \$ 1,06 \mathrm{t}^{-1}$, limpeza de $\mathrm{R} \$ 1,44 \mathrm{t}^{-1}$ (5\% de impurezas), secagem de $\mathrm{R} \$ 11,28 \mathrm{t}^{-1}$ (redução $20 \%$ para $13 \%$ de umidade), armazenamento de $\mathrm{R} \$ 1,31 \mathrm{t}^{-1}$ quinzena $^{-1}$, expedição $\mathrm{R} \$ 1,75 \mathrm{t}^{-1}$ e mais uma taxa administrativa de $10 \%$ sobre o montante. Os valores citados foram obtidos junto à Companhia Nacional de Abastecimento 
(CONAB, 2006) e o do transporte e pesagem, no Anuário da Agricultura de 2005 (AGRINUAL 2005).

Analisou-se, também, a comercialização dos grãos de milho, logo após a colheita, estando esses sujeitos a um deságio nos preços vigentes. Com informações obtidas junto a empresas privadas, cooperativas e alguns pequenos produtores, considerou-se deságio de $15 \%$ no preço da saca de milho úmido.

A viabilidade econômica foi avaliada pela receita líquida, que resultou da subtração da receita bruta da comercialização do milho pelo custo de produção e de secagem/ou deságio do produto úmido.

\section{RESULTADOS E DISCUSSÃO}

Para a avaliação da viabilidade econômica na aquisição do silo-secador, desenvolveu-se uma planilha eletrônica, de simulações econômicas, estimando a rentabilidade dos pequenos agricultores em função das seguintes variáveis: tamanho das áreas de produção, níveis de produtividade e diferentes preços de mercado da saca de milho.

Foram feitos levantamentos detalhados dos custos fixos e dos variáveis, para implantação da unidade de secagem de grãos. A seguir, são discriminados os itens que compõem os custos deste tipo de investimento, adequando-os à realidade do setor agrícola nacional.

\section{Custos fixos}

Através de um levantamento detalhado do custo para pequenos produtores rurais paulistas, verificou-se que os custos da lavoura são compostos, basicamente, de custos variáveis, devido aos mesmos não possuírem nenhuma máquina ou implemento agrícola. Consideraram-se, apenas, os custos fixos para aquisição do silo-secador, sendo calculado com base na taxa de juros sobre o capital, depreciação e gastos de manutenção.

Na Tabela 1, é apresentado o modelo e custo do silo-secador para cada tamanho de propriedade e nível de produtividade, procurando utilizar o modelo que mais se enquadrasse em cada situação simulada.

TABELA 1. Capacidade, preço e custos fixos dos modelos de silo-secador, por volume de produção.

\begin{tabular}{|c|c|c|c|c|c|c|c|c|}
\hline \multirow{3}{*}{$\begin{array}{c}\text { Áreas de } \\
\text { Produção } \\
\text { (ha) }\end{array}$} & \multirow{3}{*}{$\begin{array}{c}\text { Produtividade } \\
\text { do Milho } \\
\left(\text { saca ha }^{-1}\right)\end{array}$} & \multirow{3}{*}{$\begin{array}{l}\text { Volume } \\
\text { Produzido } \\
\left(\mathrm{m}^{3}\right)^{*}\end{array}$} & \multicolumn{6}{|c|}{ Silo-Secador } \\
\hline & & & \multirow{2}{*}{ Modelo } & \multirow{2}{*}{$\begin{array}{c}\text { Capacidade } \\
\left(\mathrm{m}^{3}\right)\end{array}$} & \multirow{2}{*}{ Preço $(\mathrm{R} \$)^{* *}$} & \multicolumn{3}{|c|}{ Custos Fixos $\left(\mathrm{R} \$\right.$ ano $\left.^{-1}\right)$} \\
\hline & & & & & & Deprec. & Juros & Manut \\
\hline \multirow{3}{*}{10} & 65 & 55 & SAF 46460 & 76,45 & $11.750,00$ & 783,33 & 587,50 & 235,00 \\
\hline & 75 & 64 & SAF & 76,45 & & 783,33 & 587,50 & 235,00 \\
\hline & 85 & 72 & SAF 46460 & 76,45 & $11.750,00$ & 783,33 & 587,50 & 235,00 \\
\hline \multirow{3}{*}{20} & 65 & 111 & SAF 62600 & 181,14 & $16.980,00$ & $1.132,00$ & 849,00 & 339,60 \\
\hline & 75 & 128 & SAF 62600 & 18 & $16.980,00$ & $1.132,00$ & 849,00 & 339,60 \\
\hline & 85 & 145 & SAF 62600 & 181,14 & $16.980,00$ & $1.132,00$ & 849,00 & 339,60 \\
\hline \multirow{3}{*}{30} & 65 & 166 & SAF 62600 & 181,14 & $16.980,00$ & $1.132,00$ & 849,00 & 339,60 \\
\hline & 75 & 192 & SAF 70600 & 230,91 & $18.930,00$ & $1.262,00$ & 946,50 & 378,60 \\
\hline & 85 & 217 & SAF 70600 & 230,91 & $18.930,00$ & $1.262,00$ & 946,50 & 378,60 \\
\hline \multirow{3}{*}{40} & 65 & 222 & SAF 70600 & 230,91 & $18.930,00$ & $1.262,00$ & 946,50 & 378,60 \\
\hline & 75 & 256 & SAF 70600 & 230,91 & $18.930,00$ & $1.262,00$ & 946,50 & 378,60 \\
\hline & 85 & 290 & SAF 70600 & 230,91 & $18.930,00$ & $1.262,00$ & 946,50 & 378,60 \\
\hline
\end{tabular}

* A massa específica média do milho é de $704 \mathrm{~kg} \mathrm{~m}^{-3}$ (ASAE, 2000).

** Preço obtido junto ao Grupo Fockink em 16-3-2006.

Todos os modelos vêm acompanhados de um kit, composto por um tubo e uma rosca para realizar a descarga do silo, bem como um monitor que permite a automação do silo-secador. Nas propriedades em que o volume de produção ultrapassou a capacidade do silo-secador, considerou- 
se o excedente vendido logo após a colheita, descontando as despesas com transporte, recepção, limpeza e secagem.

\section{Custos variáveis}

Nos sistemas de secagem com ar em temperatura próxima à ambiente, o principal fator na composição do custo variável foi a energia elétrica gasta para acionar o ventilador. Assim, estimaram-se o custo e o consumo de energia elétrica, de acordo com o volume produzido em cada propriedade (Tabela 2). A mão-de-obra também foi calculada para cada unidade produtiva, levando em consideração a produção da mesma, como mostrada na Tabela 2.

TABELA 2. Custos variáveis de energia elétrica e de mão-de-obra do silo - secador em função das áreas de produção.

\begin{tabular}{|c|c|c|c|c|c|c|c|}
\hline \multirow{3}{*}{$\begin{array}{l}\text { Áreas de } \\
\text { Produção } \\
\text { (ha) }\end{array}$} & \multirow{3}{*}{$\begin{array}{l}\text { Produtividade } \\
\text { do Milho } \\
\left(\text { saca ha }^{-1}\right)\end{array}$} & \multirow{3}{*}{$\begin{array}{c}\text { Volume } \\
\text { Produzido } \\
\left(\mathrm{m}^{3}\right)^{*}\end{array}$} & \multicolumn{5}{|c|}{ Silo-Secador } \\
\hline & & & \multirow[b]{2}{*}{ Modelo } & \multicolumn{2}{|c|}{ Energia Elétrica } & \multicolumn{2}{|c|}{ Mão-de-Obra } \\
\hline & & & & $\begin{array}{c}\text { Consumo } \\
(\mathrm{kW})\end{array}$ & $\begin{array}{l}\text { Preço Final } \\
\text { (R\$) }\end{array}$ & Horas (h) & $\begin{array}{l}\text { Preço Final } \\
\text { (R\$) }\end{array}$ \\
\hline \multirow{3}{*}{10} & 65 & 55 & SAF 46460 & 553,98 & 211,17 & 13,85 & 29,36 \\
\hline & 75 & 64 & SAF 46460 & 639,20 & 244,28 & 15,98 & 33,88 \\
\hline & 85 & 72 & SAF 46460 & 724,43 & 276,85 & 18,11 & 38,39 \\
\hline \multirow{3}{*}{20} & 65 & 111 & SAF 62600 & $1.107,95$ & 423,41 & 27,70 & 58,72 \\
\hline & 75 & 128 & SAF 62600 & $1.278,41$ & 488,55 & 31,96 & 67,76 \\
\hline & 85 & 145 & SAF 62600 & $1.448,86$ & 553,69 & 36,22 & 76,79 \\
\hline \multirow{3}{*}{30} & 65 & 166 & SAF 62600 & $1.661,93$ & 635,12 & 41,55 & 88,08 \\
\hline & 75 & 192 & SAF 70600 & $1.917,61$ & 732,83 & 47,94 & 101,63 \\
\hline & 85 & 217 & SAF 70600 & $2.173,30$ & 830,54 & 54,33 & 115,18 \\
\hline \multirow{3}{*}{40} & 65 & 222 & SAF 70600 & $2.215,93$ & 846,43 & 55,40 & 117,44 \\
\hline & 75 & 256 & SAF 70600 & $2.556,82$ & 977,11 & 63,92 & 135,51 \\
\hline & 85 & 290 & SAF 70600 & $2.897,73$ & $1.107,3$ & 72,44 & 153,58 \\
\hline
\end{tabular}

* A massa específica média do milho é de $704 \mathrm{~kg} \mathrm{~m}^{-3}$ (ASAE, 2000).

\section{Custos totais da secagem}

Na Tabela 3, são apresentados os custos de secagem/armazenagem do grão, para as duas alternativas que envolveram o processamento pós-colheita, e as despesas com o deságio, para a hipótese de comercialização do produto úmido.

TABELA 3. Custos de secagem/armazenagem e despesas com deságio na comercialização do produto úmido.

\begin{tabular}{|c|c|c|c|c|c|c|c|c|c|c|c|c|c|c|c|}
\hline \multirow{5}{*}{$\begin{array}{l}\text { Ar. } \\
\text { de } \\
\text { Pr. } \\
\text { (ha) }\end{array}$} & \multirow{5}{*}{$\begin{array}{l}\text { Prod. } \\
\text { Milho } \\
\text { (sc/ha) }\end{array}$} & \multicolumn{14}{|c|}{ Custos } \\
\hline & & \multicolumn{6}{|c|}{ Aquisição do Silo-Secador (R \$/Ano) } & \multicolumn{6}{|c|}{ Comercialização do Produto Úmido (R\$) } & \multirow{2}{*}{\multicolumn{2}{|c|}{$\begin{array}{l}\text { Terceirização da } \\
\text { Secagem e } \\
\text { Armazenamento } \\
\text { por } 6 \text { meses (R) }\end{array}$}} \\
\hline & & \multicolumn{6}{|c|}{ Preço da Saca } & \multicolumn{6}{|c|}{ Preço da Saca } & & \\
\hline & & \multicolumn{2}{|c|}{$\mathrm{R} \$ 13,03$} & \multicolumn{2}{|c|}{$\mathrm{R} \$ 19,69$} & \multicolumn{2}{|c|}{$\mathrm{R} \$ 34,29$} & \multicolumn{2}{|c|}{$\mathrm{R} \$ 13,03$} & \multicolumn{2}{|c|}{$\mathrm{R} \$ 19,69$} & \multicolumn{2}{|c|}{$\mathrm{R} \$ 34,29$} & & \\
\hline & & Total & Sc & otal & sc & Total & $\mathrm{sc}$ & Total & $\mathrm{sc}$ & Total & 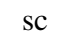 & Total & sc & Total & sc \\
\hline \multirow{3}{*}{10} & 6 & 907,05 & 93 & 0 & 2,98 & 05,20 & 3,08 & $1.270,43$ & 1,95 & 0 & 2,95 & o & 5,14 & 1.44 & 2,22 \\
\hline & 7 & 953,39 & 2,60 & 7 & 2,65 & $2.066,64$ & 2,76 & $1,465,88$ & 1,95 & & 2,95 & 63 & 5,14 & 79 & 2,22 \\
\hline & 8 & 9,74 & 2,35 & 4 & 2,40 & $2.128,08$ & 2,50 & 61,33 & 1,95 & & 2 & & 5,14 & 16 & 2,22 \\
\hline \multirow{3}{*}{20} & & & 5 & & 2, & & 2,40 & 85 & 1 , & & & & 14 & & 2,22 \\
\hline & 1 & & 2,01 & & 2,06 & & 2,16 & 75 & 1,95 & & & & 5,14 & 3.3 & 2,22 \\
\hline & 85 & 41 & 1,83 & & 1,88 & & 1,98 & 2,65 & 1,95 & & 2,95 & & 5,14 & 3.78 & 2,22 \\
\hline \multirow{3}{*}{30} & 65 & 24,26 & 1,65 & & 1,70 & & 1,80 & $3.811,28$ & 1,95 & & 2,95 & & 5,14 & 25 & 2,22 \\
\hline & 75 & $3.629,78$ & 1,61 & $3.736,21$ & 1,66 & $3.969,52$ & 1,76 & $4.397,63$ & 1,95 & & 2,95 & $11.572,88$ & 5,14 & $5.003,37$ & 2,22 \\
\hline & 85 & 68,81 & 1,48 & $3.889,43$ & 1,53 & $4.153,84$ & 1,63 & $4.983,98$ & 1,95 & $7.531,43$ & 2,95 & $13.115,93$ & 5,14 & $5.670,49$ & 2,22 \\
\hline \multirow{3}{*}{40} & 65 & 91,98 & 1,46 & $3.914,96$ & 1,51 & $4.184,56$ & 1,61 & $5.081,70$ & 1,95 & $7.679,10$ & 2,95 & $13.373,10$ & 5,14 & $5.781,67$ & 2,22 \\
\hline & 75 & 42,65 & 1,42 & & 1,47 & & 1,57 & $5.863,50$ & 1,95 & & 2,95 & & 5,14 &, 16 & 2,22 \\
\hline & 85 & $3.842,65$ & 1,42 & $3.970,81$ & 1,47 & $4.251,75$ & 1,57 & $6.645,30$ & 1,95 & $10.041,90$ & 2,95 & $17.487,90$ & 5,14 & $7.560,65$ & 2,22 \\
\hline
\end{tabular}


Os custos envolvidos na hipótese de aquisição do silo-secador sofreram redução com o aumento de produtividade do milho e, também, com o aumento da área plantada; isto ocorre devido à diluição dos custos fixos. O silo-secador apresentou os menores custos por saca em todas as áreas de produção de 20 (na produtividade de 85 sacas/ha), 30 e 40 ha, ou seja, não houve interferência do preço de comercialização do milho. Ao preço de $\mathrm{R} \$ 13,03 \mathrm{saca}^{-1}$, nas áreas de produção de $10 \mathrm{e}$ 20 ha (nas produtividades de 65 e 75 sacas por ha), os menores custos foram encontrados na comercialização úmida do produto.

\section{Receita líquida}

$\mathrm{Na}$ Tabela 4, são apresentados os resultados das análises econômicas para as três situações hipotéticas: Aquisição do Silo-Secador, Terceirização da Secagem/Armazenamento e Comercialização Úmida do Produto.

TABELA 4. Variação da receita líquida obtida pelo produtor nas três hipóteses simuladas.

\begin{tabular}{|c|c|c|c|c|c|c|c|c|c|c|}
\hline \multirow{5}{*}{$\begin{array}{l}\text { Ar. } \\
\text { de } \\
\text { Pr. } \\
\text { (ha) }\end{array}$} & \multirow{5}{*}{$\begin{array}{l}\text { Prod. } \\
\text { Milho } \\
\text { (sc/ha) }\end{array}$} & \multicolumn{9}{|c|}{ Receita Líquida $(\mathrm{R} \$)$} \\
\hline & & \multicolumn{3}{|c|}{ Aquisição do Silo-Secador (R\$/Ano) } & \multicolumn{3}{|c|}{$\begin{array}{l}\text { Comercialização do } \\
\text { Produto Úmido }(\mathrm{R} \$)\end{array}$} & \multicolumn{3}{|c|}{$\begin{array}{c}\text { Terceirização da Secagem e } \\
\text { Armazenamento por } 6 \text { meses }(\mathrm{R} \$)\end{array}$} \\
\hline & & \multicolumn{3}{|c|}{ Preço da Saca } & \multicolumn{3}{|c|}{ Preço da Saca } & \multicolumn{3}{|c|}{ Preço da Saca } \\
\hline & & $\mathrm{R} \$ 13,03$ & $\mathrm{R} \$ 19,69$ & $\mathrm{R} \$ 34,29$ & $\mathrm{R} \$ 13,03$ & $\mathrm{R} \$ 19,69$ & $\mathrm{R} \$ 34,29$ & $\mathrm{R} \$ 13,03$ & $\mathrm{R} \$ 19,69$ & $\mathrm{R} \$ 34,29$ \\
\hline & & Total & Total & Total & Total & Total & Total & Total & Total & Total \\
\hline \multirow{3}{*}{10} & 65 & $-5.176,35$ & $-878,10$ & $8.544,50$ & $-4.539,73$ & $-860,08$ & $7.206,43$ & $-4.714,72$ & $-385,72$ & $9.104,28$ \\
\hline & 75 & - 3.919,69 & $1.039,83$ & $11.912,06$ & $-3.432,18$ & 813,58 & $10.121,08$ & - 3.634,09 & $1.360,91$ & $12.310,91$ \\
\hline & 85 & - 2.663,04 & $2.957,76$ & $15.279,62$ & $-2.324,63$ & $2.487,23$ & $13.035,73$ & $-2.553,46$ & $3.107,54$ & $15.517,54$ \\
\hline \multirow{3}{*}{20} & 65 & $-9.461,64$ & $-865,13$ & $17.980,07$ & $-9.079,45$ & $-1.720,15$ & $14.412,85$ & $-9.429,44$ & $-771,44$ & $18.208,56$ \\
\hline & 75 & $-6.948,32$ & $2.970,73$ & $24.715,19$ & $-6.864,35$ & $1.627,15$ & $20.242,15$ & - $7.268,18$ & $2.721,82$ & $24.621,82$ \\
\hline & 85 & $-4.435,01$ & $6.806,58$ & $31.450,30$ & $-4.649,25$ & $4.974,45$ & $26.071,45$ & $-5.106,92$ & $6.215,08$ & $31.035,08$ \\
\hline \multirow{3}{*}{30} & 65 & $-13.032,16$ & $-137,40$ & $28.130,40$ & $-13.619,18$ & $-2.580,23$ & $21.619,28$ & $-14.144,15$ & $-1.157,15$ & $27.312,85$ \\
\hline & 75 & $-9.528,68$ & $5.349,89$ & $37.966,58$ & $-10.296,53$ & $2.440,73$ & $30.363,23$ & - $10.902,27$ & $4.082,73$ & $36.932,73$ \\
\hline & 85 & $-5.758,71$ & $11.103,67$ & $48.069,26$ & $-6.973,88$ & $7.461,68$ & $39.107,18$ & - 7.660,39 & $9.322,61$ & $46.552,61$ \\
\hline \multirow{3}{*}{40} & 65 & $-16.869,18$ & 323,84 & $38.014,24$ & $-18.158,90$ & $-3.440,30$ & $28.825,70$ & $-18.858,87$ & $-1.542,87$ & $36.417,13$ \\
\hline & 75 & $-15.795,33$ & $7.648,44$ & $51.167,50$ & $-13.728,70$ & $3.254,30$ & $40.484,30$ & - $14.536,36$ & $5.443,64$ & $49.243,64$ \\
\hline & 85 & $-11.265,31$ & $14.842,45$ & $64.201,51$ & $-9.298,50$ & $9.948,90$ & $52.142,90$ & $-10.213,85$ & $12.430,15$ & $62.070,15$ \\
\hline
\end{tabular}

A condição menos favorável, com déficit líquido de $\mathrm{R} \$ 18.858,87$, ocorreu na terceirização da secagem/armazenagem do milho produzido na maior área (40 ha) e com a menor produtividade (65 sc ha ${ }^{-1}$ ). Por outro lado, a situação mais favorável, pagando $\mathrm{R} \$ 64.201,51$, foi obtida com a aquisição do silo-secador para processar os grãos produzidos na maior área e na maior produtividade $\left(85 \mathrm{sc} \mathrm{ha}^{-1}\right)$.

Observa-se que a receita líquida foi negativa em todas as hipóteses simuladas com o preço mínimo da saca de milho, ou seja, o preço de $\mathrm{R} \$ 13,03$ não pagou nem os custos de produção, indicando que o produtor, nesta condição, não tem capacidade financeira para adquirir o silosecador. O mesmo aconteceu para o preço médio $(\mathrm{R} \$ 19,69)$ na menor produtividade (65 sacos ha $\left.{ }^{-1}\right)$, nas áreas de 10, 20 e 30 ha.

Comparando as rentabilidades ao adquirir o secador, terceirizar o processo $\mathrm{e}$ a comercialização do produto úmido, nota-se superioridade da receita líquida na aquisição do sistema de secagem/armazenagem nas propriedades de 20 (nas faixas de produtividade de 75 e 85 sacas por ha), 30 e 40 ha, em todos os níveis de produtividades e preços de comercialização da saca. A alternativa de terceirização da secagem/armazenamento apresentou as melhores receitas nas áreas de produção de 10 ha (em todas as produtividades) e 20 ha (produtividade de 65 sacas ha $^{-1}$ ), nos preços médio e máximo da comercialização.

Nas simulações de aquisição do equipamento de secagem, observa-se menor rentabilidade, principalmente, para as áreas de 10 ha, comparada à rentabilidade da terceirização da secagem. Pode-se atribuir essa receita líquida menor aos altos custos fixos que não se diluem numa única safra por ano. 
Na comercialização de grãos úmidos, encontraram-se as menores rentabilidades, exceto na área cultivada com 10 ha, ao preço de $\mathrm{R} \$ 13,03 \mathrm{saca}^{-1}$, por causa dos altos deságios que sofre esse modelo de comercialização.

Com base na análise dos dados, nota-se que a operação de processamento dos grãos, tanto na hipótese de terceirização como na aquisição do silo-secador, constitui-se numa técnica que possibilita, na maioria dos casos, que os pequenos produtores rurais (10 a 40 hectares) otimizem suas receitas líquidas. As vantagens podem acentuar-se para aqueles produtores que adquirirem o silo, pois permite comercialização da safra em períodos mais favoráveis (preço de venda superior), além de possibilitar oferecimento de serviços de secagem de grãos (receita adicional).

\section{CONCLUSÕES}

A aquisição do silo-secador foi a alternativa mais rentável nas propriedades de 20 ha (com produtividades de 4.500 e $5.100 \mathrm{~kg} \mathrm{ha}^{-1}$ ), 30 ha e 40 ha nos vários níveis de produtividade (3.900; 4.500 e $5.100 \mathrm{~kg} \mathrm{ha}^{-1}$ ), sempre que o preço de comercialização da saca do milho cobriu os custos anuais do sistema.

A terceirização da secagem/armazenagem foi a opção mais rentável nas áreas de 10 ha (para preços médio e máximo) e 20 ha (na menor produtividade).

Em todas as situações testadas, a comercialização do produto úmido nunca se constituiu na opção mais rentável.

Os resultados derivados da simulação econômica possibilitaram agregar maiores informações, demonstrando, em cada situação, a alternativa mais vantajosa financeiramente.

\section{AGRADECIMENTO}

Ao Grupo FOCKINK, pela cessão do Silo - Alambrado Ventilável.

\section{REFERÊNCIAS}

ASAE DD 241.4. Density, specific gravity and mass-moisture relationships of grain for storage. In: ASAE standards 2000. St. Joseph, 2000. p.504-6.

AGRIANUAL 2006: anuário da agricultura brasileira. 10.ed. São Paulo: FNP, 2005. p.424.

BESKOW, P.; DECKERS, D. Legislação brasileira de armazenamento de grãos. In: LORINI, I.;

MIIKE, L.H.; SCUSSEL, V. Armazenagem de grãos. Campinas: Instituto Bio Geneziz, 2002. p.2753.

CPFL. Companhia Paulista de Força e Luz. Disponível em: <http://www.cpfl.com.br>. Acesso em: 8 ago. 2006.

CONAB. Companhia Nacional de Abastecimento. Disponível em: < http://www.conab.gov.br>. Acesso em: 8 ago. 2006.

EMBRAPA. Empresa Brasileira de Pesquisa Agropecuária. Disponível em: < http://www.embrapa.br>. Acesso em: 25 maio 2001.

FAO - Food and Agriculture Organization of the United Nations. Post-harvest operations.

Disponível em: < http://www.fao.org/inpho/compend/toc_main.htm >. Acesso em: 6 nov. 2003.

FERREIRA, W.A.; BIAGGIONI, M.A.M.; GONÇALVES, V.A.; SAGLIETTI, J.R.C.

Procedimentos de acionamento de ventilador para aeração de grãos de milho, em Botucatu - SP. In: CONGRESSO BRASILEIRO DE ENGENHARIA AGRÍCOLA, 19., 1990, Piracicaba. Anais... Piracicaba: SBEA, 1990. p.1083-91.

FGV - Fundação Getulio Vargas. IGP - Índice Geral de Preços. Disponível em: <http://www.fgv.br>. Acesso em: 8 ago. 2006. 
IBGE - Instituto Brasileiro de Geografia e Estatística. Dados referentes à produção de grãos. Disponível em: <http://www.ibge.gov.br>. Acesso em: 12 set. 2004.

IEA - Instituto de Economia Agrícola. Agência Paulista de Tecnologia dos Agronegócios. Governo do Estado de São Paulo. Disponível em: <http://www.iea.sp.gov.br>. Acesso em: 23 mar. 2006.

MARTINS, R.R.; FRANCO, J.B.R.; OLIVEIRA, P.A .V.; ANGONESE, C. Armazéns para propriedade familiar. In: LORINI, I.; MIIKE, L. H.; SCUSSEL, V. Armazenagem de grãos. Campinas: Instituto Bio Geneziz, 2002. p.117-55.

PORTELLA, J.A.; EICHELBERGER, L. Secagem de grãos. Passo Fundo: Embrapa Trigo, 2001. $194 \mathrm{p}$.

SILVA, J. de S. Pré-processamento de produtos agrícolas. Juiz de Fora - MG: Instituto Maria, 1995. $509 \mathrm{p}$.

SILVA, J. de S.; CAMPOS, M.G.; SILVEIRA, S.F.R. Armazenagem e comercialização de grãos no Brasil. In: SILVA, J. de S. Secagem e armazenagem de produtos agrícolas. Viçosa: Aprenda Fácil, 2000. p.1-19.

WEBER, E. A. Excelência em beneficiamento e armazenagem de grãos. Canoas: Salles, 2005. $586 \mathrm{p}$. 